\title{
Candidate gene associations studies in psychiatry: time to move forward
}

\author{
C. Arango ${ }^{1}$
}

Published online: 9 January 2017

(C) Springer-Verlag Berlin Heidelberg 2017

In the present issue, de Castro-Sala et al. report an association between two single-nucleotide polymorphisms in the regulator of G-protein signalling 4 (RGS4) gene, a candidate gene for schizophrenia and psychotic-like experiences, in 808 healthy individuals [1]. Recent papers in this journal have focused on the genetic association between polymorphisms in candidate genes and risk behaviour [2] or associations between polymorphisms of the dopamine transporter and gene personality traits in patients with bipolar disorder [3]. None of these were published with replications in independent cohorts.

Many decades of genetic case-control association studies have produced very extensive and conflicting literature on candidate gene associations for many different complex psychiatric disorders. All these association studies have yielded an infinitude of publications with very few consistent replications.

Researchers have become sceptical of the candidate gene approach, given the plethora of associations that have failed to replicate despite highly plausible aetiological relevance after the enthusiasm over positive results from an initial study. This is even more true when interactions between candidate genes and other risk factors or environmental variables are modelled, which makes it almost impossible not to find significant findings that are later nonreplicated in independent cohorts. A recent evaluation of historical candidate genes for schizophrenia points towards inadequate statistical power as the primary reason for the

C. Arango

carango@mce.hggm.es

1 Child and Adolescent Psychiatry Department, Gregorio Marañón General University Hospital, School of Medicine, Universidad Complutense, IiSGM, CIBERSAM, Madrid, Spain lack of replication of those genes in actual genome-wide association (GWA) studies [4]. In the last decade, this has shifted the focus in psychiatric genetic research to GWA studies and to rare variance, especially for disorders such as autism, intellectual disabilities and very early-onset psychosis [5-7].

The polygenic risk score seems to be the preferred way to address the complexity of psychiatric disorders in which there is a combination of low variance explained and high heritability as measured by genome-wide complex trait analysis (GCTA) or twin studies [8]. Complex traits (including behavioural phenotypes used to make psychiatric diagnoses) are vastly polygenic and affected by a large number of variants. The polygenic score takes into account the variation in multiple genetic variants. These scores have been shown to have a better predictive power than genomewide statistically significant hits.

Since many studies (and the money spent on them) suggest that historical candidate gene associations studies are not going to provide any meaningful (or replicable) insight into the aetiology of complex disorders as we define them, for the time being, we should move towards genetic approaches that better reflect the intricacy of complex traits like psychiatric disorders in the way we categorize them.

\section{References}

1. De Castro-Sala M, Cristóbal-Narváez P, Kwapil TR et al (2016) Association between RGS4 variants and psychotic-like experiences in nonclinical individuals. Eur Arch Psychiatry Clin Neurosci. doi:10.1007/s00406-016-0676-7

2. Antypa N, Souery D, Tomasini M et al (2016) Clinical and genetic factors associated with suicide in mood disorder patients. Eur Arch Psychiatry Clin Neurosci 266:181-193 
3. Huang CC, Lu RB, Yen $\mathrm{CH}$ et al (2015) Dopamine transporter gene may be associated with bipolar disorder and its personality traits. Eur Arch Psychiatry Clin Neurosci 265:281-290

4. Farrell MS, Werge T, Sklar P, Owen MJ et al (2015) Evaluating historical candidate genes for schizophrenia. Mol Psychiatry 20:555-562

5. Gizer IR, Ficks C, Waldman ID (2009) Candidate gene studies of ADHD: a meta-analytic review. Hum Genet 126:51-90

6. Geschwind DH, State MW (2015) Gene hunting in autism spectrum disorder: on the path to precision medicine. Lancet Neurol 14:1109-1120
7. Fraguas D, Díaz-Caneja CM, State MW et al (2016) Mental disorders of known aetiology and precision medicine in psychiatry: a promising but neglected alliance. Psychol Med 23:1-5

8. Gandal MJ, Leppa V, Won H, Parikshak NN, Geschwind DH (2016) The road to precision psychiatry: translating genetics into disease mechanisms. Nat Neurosci 19:1397-1407 